\title{
Numerical simulation study of oil diffusion at low tide near the port area of Ma'ao, Zhoushan
}

\author{
Junyan Dong ${ }^{1, *}$, Zhibo Tang ${ }^{1}$, Hao Zeng ${ }^{2}$, Zhihu Mei ${ }^{1}$, Ruishan Hang ${ }^{1}$, and Lei Chen ${ }^{1}$ \\ ${ }^{1}$ College of Marine and Engineering Equipment, Zhejiang Ocean University, China \\ ${ }^{2}$ Zhejiang Qiming Marine Power Engineering Company, China
}

\begin{abstract}
In this paper, the numerical hydrodynamic simulation has been carried out by using measured topographic data and related tidal information. The oil particle tracking module of MIKE21 is adopted to study the processes of drifting and turbulent diffusion of oil particles on the water surface, where four working conditions, namely, static wind, dominant wind direction, maximum wind direction and most unfavourable wind direction, are applied. Results show that Xiushan Island will be the apparent 'victim' in the cases of oil spill in all wind directions. Meanwhile, due to the existence of Changbai Island and Xiushan Island, the diffusion process of oil particles is obviously retarded to impact the protected marine areas.
\end{abstract}

\section{Introduction}

With the increase of oil tanker terminals along the coast of Zhoushan, the risk of oil spill arises. The process of oil spill diffusion is complicated, and it causes serious impact on various sensitive points of the island to a great extent, especially the culture function areas. Project becomes more, the channel narrower ${ }^{[1][2]}$, and accidental oil spills are more likely to occur. It is noteworthy that oil spills are related to not only meteorological conditions such as high and low tides and wind conditions, but also the physical and chemical properties of the oil, regarded as crucial roles. Therefore, our research team conducts a very necessary simulation of oil spill risk in the area of the tanker terminal to explore the oil film drift pattern, spatial and temporal distribution, as well as the degree of impact on each sensitive area, so as to provide a scientific basis for improving the timeliness and accuracy of the emergency decision when the risk occurs in order to reduce the impact of oil spills.

\section{Oil spill model study and selection}

Among foreign scholars, Fay ${ }^{[3]}$ tried force analysis on oil film diffusion and divided oil spill expansion into three stages. Mackay ${ }^{[4]}$ integrated wind speed and oil spill volume while adding the empirical equation of evaporation to make it the basic theory of oil spill weathering. Johansen ${ }^{[5]}$ applied Lagrange tracing method to oil particle modelm, where clearly show the actual situation of oil film under wind and wave. Later, Suh ${ }^{[6]}$ et al. applied Euler-Lagrange model for mixed-method particle tracking to simulate coastal dispersion to improve the accuracy. Wind is an important factor for oil spill dispersion. For this reason, the Coast Guard model proposed by Mil ${ }^{[7]}$, the SEADOCK model by Williams ${ }^{[8]}$, and the Nay model established by Webb ${ }^{[9]}$ consider the role of wind. However, few researchers have analysed the characteristics of oil itself.

The oil spill model is divided into roughly the following three types, which are Oilmap model, GNOME model and MIKE21 ecological oil spill model. Since Oilmap model is commonly used in surface diffusion situations, it is not an open source model. And GNOME cannot show the dynamic changes of oil spill perfectly. However, MIKE21, an advanced simulation software tool with GUI functions, can cover all the issues above. Danish Institute of Water Research developed MIKE21, which is based on the Lagrangian principle, to simulate the oil spill diffusion, with certain reasonable conditions. The software can more comprehensively respond to the complex changes of oil film drift trajectory and coverage in the compound and changing water environment.

\section{Selection of oil spill sites used for numerical calculations}

From previous literature ${ }^{[2]}$, it is found that accidental oil spills from harbor ships in Zhoushan ocean areas are mainly caused by reefing and ship collisions in bad weather. The vicinity of Ma'ao port distinct, is selected as the oil spill area as shown in figure 1.

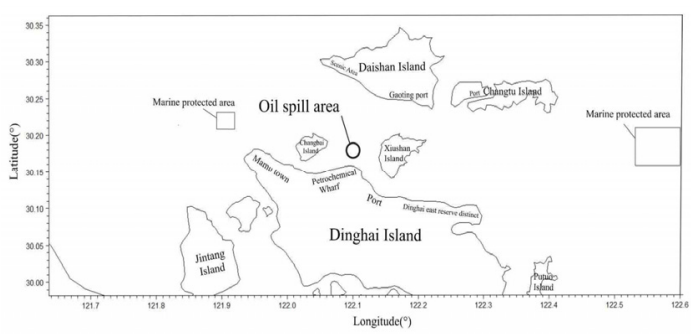

Fig. 1. Location map of the oil spill area

\footnotetext{
*Corresponding author: 2904736384@qq.com
} 


\section{Mesh Construction}

The model calculation area starts from Hangzhou City in the west, north to the East China Sea Bridge and Shanghai, south to Xiangshan, and east to $123.4 \mathrm{E}$ longitude, which covers Hangzhou Bay and Zhoushan Islands ocean area. The mesh near the port terminal is dense and the minimum mesh size reaches 30 meter. The topography and shoreline of the area can be immortally depicted to ensure sufficient calculation accuracy. The mesh is sparse in the offshore area far away from the oil spill point. Because of the many islands in Zhoushan leading to a particularly curved shoreline, the triangular mesh fits the shoreline better. Therefore, the model which has 9695 nodes and 18014 cells uses SMS to construct triangular meshes.

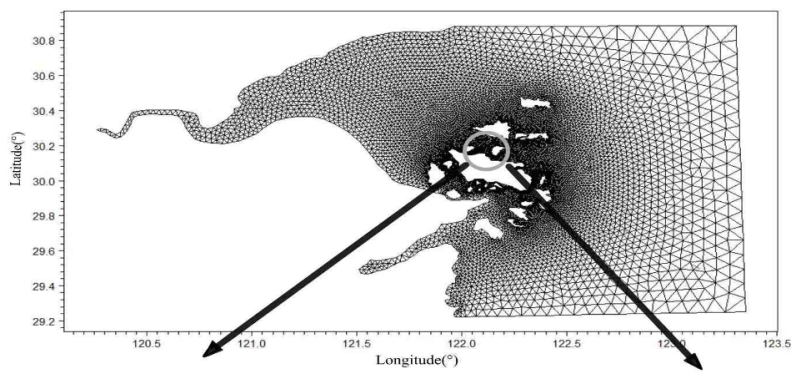

Fig. 2. Large-scale mesh map

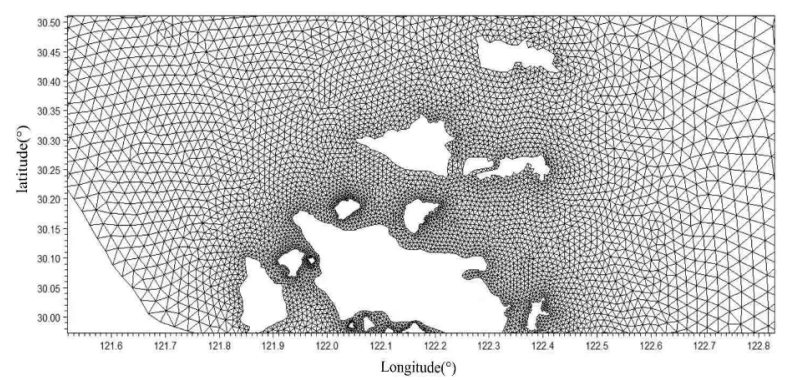

Fig. 3. Local mesh diagram

\section{Model parameter settings, results and validation}

The model calculation time step needs to consider the accuracy of the calculation, in order to keep the model calculation stable, the minimum time step size is $0.0001 \mathrm{~s}$ and the maximum is $30 \mathrm{~s}$. The roughness of the model adopts the Manning coefficient, value is 0.014 , where the side beach is taken as $0.025 \sim 0.033$. The model adopts a cold start, and the Courant number limit is 0.8 . The upper boundary is controlled by flow, and the outer boundary condition is controlled by the time series of tide level provided by the China Sea University model. The model uses the dynamic boundary processing technique. ${ }^{[11]}$

We have selected the tide level and tide validation from observation data for the 2019 spring hydrographic test period, and the numerical simulation results showed that each measured values and the simulated ones are highly matched. Depending on the simulation results, it could basically reflect the tidal characteristics of the region.

\section{Parameters}

Attempts have been made to one of the oil spill point which is located in the northern sea area of Ma'ao port area. According to the recommended method by "ship pollution marine environment risk evaluation technical specification (for trial implementation)", fuel oil load is equal to fuel oil tank maximum load timed by real rate. Estimated amount of fuel leakage from oil tank into the sea is about $50 \mathrm{t}$.

According to the statistical history of the nearby meteorological station, the calculated wind conditions are selected as follows: static wind, the most unfavourable wind $6 \mathrm{~m} / \mathrm{s}$, the dominant wind direction $4.8 \mathrm{~m} / \mathrm{s}$ and the maximum wind direction $10.8 \mathrm{~m} / \mathrm{s}$. Compared among the divisions of the sensitivity of all functional areas, the area on the east side is more sensitive than the west. It is straight forward to choose the falling tide to explore, as a result,

Table 1. Table of calculation conditions

\begin{tabular}{cccc}
\hline $\begin{array}{c}\text { Size of } \\
\text { oil spill }\end{array}$ & Direction of wind & $\begin{array}{c}\text { Wind speed } \\
(\mathrm{m} / \mathrm{s})\end{array}$ & $\begin{array}{c}\text { Form of } \\
\text { tide }\end{array}$ \\
\hline $50 \mathrm{t}$ & $\begin{array}{c}\text { Silent wind } \\
\text { Dominant wind direction } \\
\text { (summer) (SE) } \\
\text { Maximum wind direction } \\
(\mathrm{S})\end{array}$ & 0 & low tide \\
& $\begin{array}{c}\text { Most unfavorable wind } \\
\text { direction (NWW) }\end{array}$ & 10.8 & low tide \\
& 6 & low tide \\
\hline
\end{tabular}

\section{Analysis of calculation results}

\subsection{For the case of still wind}

Suppose that in the case of still wind phase at 6:00 am at low tide released $50 \mathrm{t}$ of oil which began to spread within an hour. The first impact was on the western part of Xiushan. With the influence of the falling tide, the oil particles started to move along the shoreline of Dinghai distinct, in the southeast direction at 9:00 am, it moved to the west dock of Dinghai and also passed through the southeast of Xiushan. What's worse, the shoreline south of Xiushan and the shoreline north of Dinghai were both affected to varying degrees.

At 13:00 and 14:00 of the same day, the tide was high and the particles started to move in the opposite direction, so that nearly half of the whole Xiushan Island coastline would be polluted by the oil spill, while the coastline north of Dinghai District was less affected at this time. At 8:00 pm of the same day, depending on the influence of the tide, the oil particles were mainly concentrated on the east side of Xiushan Island, and a large area of oil spill could be seen on the east side of Xiushan Island. At 6:00 on the next day, i.e. the 24th hour of the oil spill release, influenced by the high tide, oil particles can be seen mainly concentrated near Changbai Island, while some particles started to approach Dayushan and Daishan. A slice of oil particles also intruded the sea near Changtu Island. At the 54th hour, the oil particles started to move toward Putuoshan and Zhoushan main island, with trace amounts of oil particles reaching the vicinity of Changtu Island. A small portion of 
oil particles entered around Putuoshan by the 66th hour.

To sum up, when the oil spill was in the state of low tide and no wind, the spread would mainly affect the area south of Daishan County and north of Dinghai District. If the oil spill could be treated in this area in time, the harm of oil spill spreading would be less.

Table 2. Total area of oil particle diffusion table

\begin{tabular}{|l|c|c|c|}
\hline Time to spill $/ \mathrm{h}$ & 12 & 24 & 36 \\
\hline Diffusion area $/ \mathrm{km}^{2}$ & 11.19 & 261.32 & 409.49 \\
\hline Time to spill $/ \mathrm{h}$ & 48 & 60 & 72 \\
\hline Diffusion area $/ \mathrm{km}^{2}$ & 657.53 & 841.71 & 1019.01 \\
\hline
\end{tabular}

The following graphs show the swept area of the sea area where the particles are located at that time, and the total swept area should sum up accordingly.

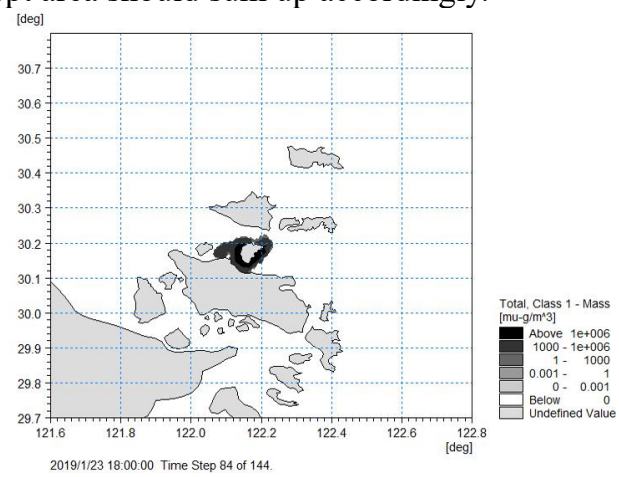

Fig. 4. Map of the swept area 12 hours after the oil spill

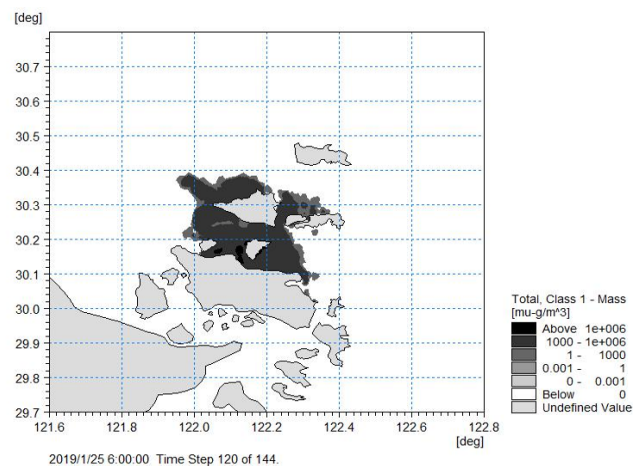

Fig. 5. Map of the swept area 48 hours after the oil spill

\subsection{When the dominant wind direction (SE) is $4.8 \mathrm{~m} / \mathrm{s}$}

Under the condition that the normal wind direction is southeast wind which is $4.8 \mathrm{~m} / \mathrm{s}$, the diffusion area is small at the beginning 1 hour. After that, according to the ebb tide period, the wind's influence is weaker, so the particles all move to the east. At 10:00 in the morning of that day, it surrounded half of Xiushan Island, but the diffusion of the sea area is less. By the joint action of the tide and the wind, part of the oil particles are close to the the southwest side of Daishan, and the remaining part of the particles remained in the oil spill release area at 18:00 in the evening. The oil particles kept moving on the north side of Xiushan Island and the south side of Daishan Island under the action of the tide.
At 20:00, the higher concentration of oil particles entered the sea near Daishan Island and Changtu Island. At 4:00 pm, the particles were divided into two sets when the effect of wind speed played a part. The west side of a wave of oil particles more scattered because of the obvious wind speed, the spread of a wider range, the east side of the particles more intensive. At 10:00 on the following day, the oil particles began to proceed along the east. Now there are three parts of oil particles, respectively, in the northwest, northeast and southwest of Daishan Island. The southwest of the oil particles attached to the island boundary line, and a small part of the impact to Qushan Island. At 16:00 on the next day, under the effect of high tide and southeast wind, the oil particles began to spread in the northwest direction. After 40 to 45 hours of oil spill occurred, part of the particles gathered on the left side of Qushan Island. The oil particles started to move to the north after another 4 hours.

Above results show that the oil spill does not affect a large area, and as long as the oil particles are controlled within 24 hours, so that the oil particles can be reduced to enter Changtu agricultural and fishery area and Shuanghe Mountain tourist and recreational area, there should not be much impact on the later period.

Table 3. Oil particle diffusion area table $h$

\begin{tabular}{|c|c|c|c|c|}
\hline Time to spill/h & 12 & 24 & 36 & 48 \\
\hline Diffusion area $/ \mathrm{km}^{2}$ & 20.5 & 528.01 & 811.59 & 1092.13 \\
\hline
\end{tabular}

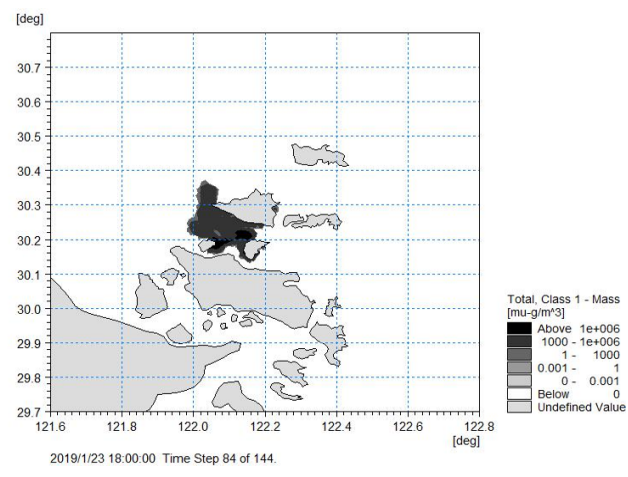

Fig. 6. Map of the swept area 12 hours after the oil spill

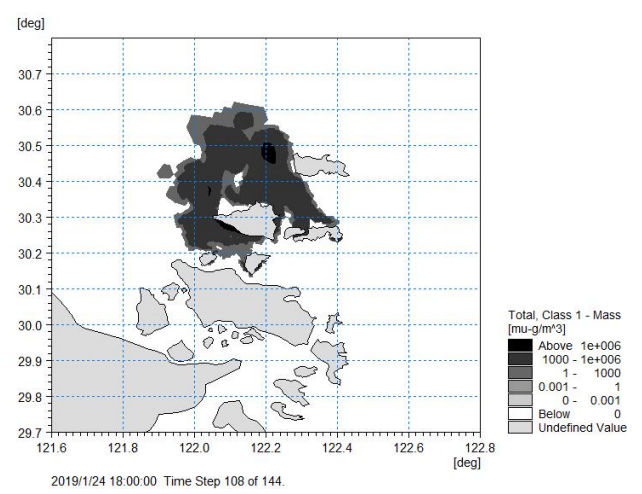

Fig. 7. Map of the swept area 36 hours after the oil spill 


\subsection{At the most unfavorable wind direction (NWW) $6 \mathrm{~m} / \mathrm{s}$}

The oil particles were released at 6:00 am in the most unfavorable wind direction. After 2 hours, due to the tide and wind, the oil particles were in the vicinity of the west pier of Dinghai, and the concentration of particles was very high. After that, these oil spill particle clusters moved eastward and reached the northeast of Dinghai. And at 13:00 on the same day, it started to stay on the coastline of Dinghai Island, probably due to the wind and tide, as a result, the oil particles were not an obvious spreading phenomenon. The oil particles stayed on the coastline of Dinghai Island for more than 6 hours, and started to move southward at 8:00. The oil particles reached the vicinity of Putuoshan island, and the whole spreading surface of the oil particles was still small at 22:00 on the same day. When at 1:00 on the second day of the oil spill, the oil particles were concentrated in the east of Dinghai Island, and the fastest oil particles had already started to approach the Shenjiamen area (the southeast of Dinghai Island). Fortunately, the oil spill did not have a large impact. At 10:00 on the second day after the oil spill occurred, the oil particles gathered around Putuo Mountain and had started the process of spreading the whole oil particles. The particles were divided into two groups moving south into the Putuo area at 14:00 pm. Most of the oil particles then moved in the southeast direction, and the diffusion rate accelerated because there were fewer islands that hindered them. Along with the tide, some particles even affected the shrimp standoff island area.

The results illustrate that under the influence of the most unfavorable wind condition and small tide, the particle diffusion phenomenon is not obvious at the beginning, and the first 12 hours is the best time to deal with the oil spill. In addition, the coastline north of Dinghai Island is an excellent place to deal with the oil spill. Afterwards, the subsequent oil spill diffusion accelerates. As a consequence, the main area affected is mainly near Putuoshan Island. Meanwhile, it can be found that the diffusion rate of oil particles is extremely low in the early stage and fast in the later stage.

Table 4. Oil particle diffusion area table

\begin{tabular}{|c|c|c|c|c|}
\hline Time to spill/h & 12 & 24 & 36 & 48 \\
\hline Diffusion area $/ \mathrm{km}^{2}$ & 15.02 & 290.75 & 423.12 & 722.78 \\
\hline
\end{tabular}

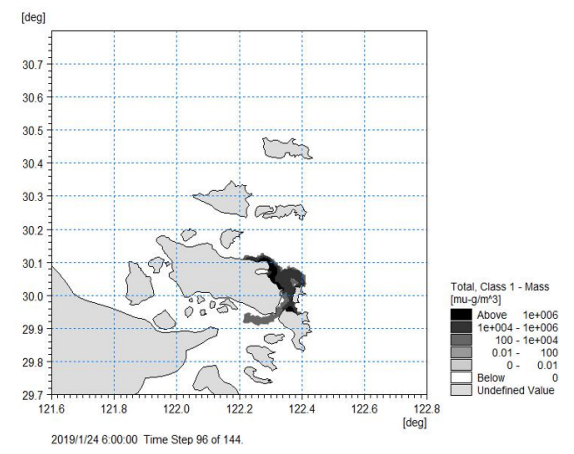

Fig. 8. Map of the swept area 12 hours after the oil spill

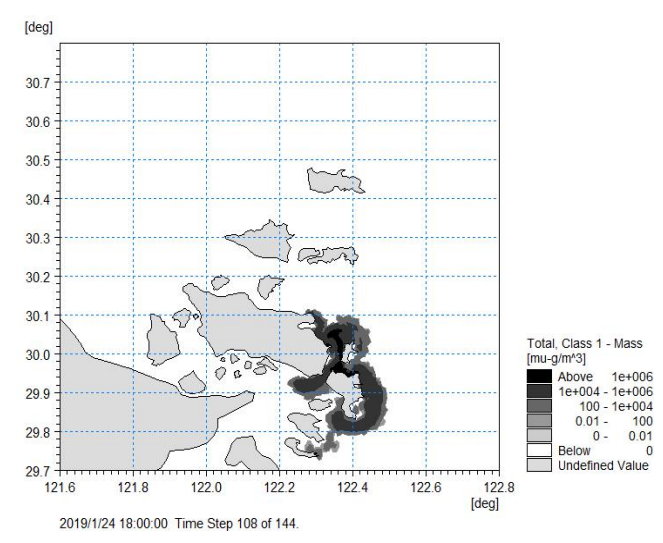

Fig. 9. Map of the swept area 48 hours after the oil spill

\subsection{Maximum wind direction (North) with $10 \mathrm{~m} / \mathrm{s}$}

At 6:00 am., $50 \mathrm{t}$ of oil particles were released. Due to the action of the tide and wind, the oil particles passed through the southern part of Daishan Island and the northern part of Xiushan Island. Three hours after the oil spill, they passed through Gaoting agricultural and fishery area, but at that time the spreading surface of the oil spill was not obvious. Furthermore, it was the praiseworthy time to deal with the oil. In the following two hours, the oil particles were in the south of Changtu Island, near the south port shipping area of Changtu Mountain. At 14:00, the diversion entered the vicinity of Changtu Island to the north, at this time, the oil particles were moving north along the shoreline, causing a certain impact on the agriculture and fishery industry. At 16:00, the fusion of the two oil particles reached the north of Changtu Island, and moved all the way to the northwest into the vicinity of Daidong (the east of Daishan island). After that at 20:00, the particles escaped to the Northeast direction, and gradually became close to Qushan tourism and recreation areas. At 24:00 of that day, arrived at the coastline of Qushan Island. On the second day of tidal action, encountered the influence of high tide, oil particles were mainly concentrated on the south coast of Qushan Island. Meanwhile, oil particles gathered more and not dispersed. The next day at 6:00, oil particles ran into the Huangze Mountain - Qushan port shipping area. The oil particles were divided into two strands, one remained on the south coast of Qushan Island, and another was on the north side of Qushan Island, remaining on the shoreline. At 17:00 on the second day, except for some remaining on the shoreline near Qushan Island, the rest of the oil particles moved to the north. Most of the oil particles were in the northern part of Qushan Island. Since the oil particles in the maximum wind direction were moving faster, the particles had exceeded the mapped area within 48 hours, so the calculation of the swept area was no longer performed.

\section{Conclusions}

With help of MIKE21, based on a mathematical model of the tide and ship oil spill in the sea area near Ma'ao port, we have studied and analyzed the numerical simulation of 
ship oil spill diffusion under different wind conditions, applied with low tide. Main conclusions are as following.

1) At low tide, the time of oil spillage particles reaching functional area block is obviously different. The influence of wind on the oil spill trajectory and affected area is larger when the working conditions are $4.8 \mathrm{~m} / \mathrm{s}$, and the impact area and oil flow trajectory are more affected by the topography when working at the most unfavourable wind direction is $6 \mathrm{~m} / \mathrm{s}$.

2) Comparing the different wind directions of oil particles, it can be found that the sea swept area of the normal wind is larger, the area swept by the static wind and the most disadvantageous wind direction is close. Where the static wind direction of the oil spill is all around the disaster areas. In the most adverse wind direction, the oil spill was greatly affected by the topography. During the first few hours of the spill, there were 25 consecutive hours when oil particles stayed in the eastern reserved area of Zhoushan.

3) Whatever the wind is, Xiushan is the most influential of all the islands. However, because of the location of Changbaishan Island and Xiushan island, the dispersion of oil particles has been blocked, the two marine protected areas have been a certain degree of protection.

\section{References}

1. Wang Shoudong, Xu Honglei. etal. Layout of oil terminals and oil spill risk assessment in Zhoushan sea area[J]. Water transport engineering, 2016.

2. Liu Shaoping, Ma Jiayi. Analysis of accidental oil spill risk in Zhoushan Port and countermeasures for prevention [C]// Annual Meeting and Symposium of the China Navigation Society Inland River Vessel Piloting Committee. China Nautical Society, 2012.

3. FAY J A. The spread of oil slicks on a calm sea[C] Oil on the Sea. New York: Plenum Press, 1969: 53-63.

4. MACKAY D, MATSUGU R.Evaporation rate of liquid hydrocarbon spills on land and water[J]. Can J Chem Eng, 1973, 51(8): 434-439.

5. Johansen ASCE Task Committee on Modeling of Oil Spills of the Water Resources Engineering Division. State-of-the-art review of modeling transport and fate of oil spills[J]. Journal of Hydraulic Engineering, 1996, 122(11): 594-609.

6. Suh S W. A hybrid approach to particle tracking and Eulerian-Lagrangian models in the simulation of coastal dispersion[J]. Environmental Modelling \& Software, 2006, 21(2): 234-242.

7. MILLER, STOLZENBACK K D. A review and evaluation of basic techniques prediction the behavior of surface oil slicks[R]. Sea Grant Program Report No. MITSG-77-9. Cambridge, United States: Massachusetts Institute of Technology, 1977, 22: 2030 .

8. WILLIAMS G N, HANN R W. Simulation models for oil spill transport and diffusion[C]. Summer Computer Simulation Conference, La Jolla, California, United States, 1975: 748-752.

9. WEBB L, TARANTO R, HASHIMOTO E. Operational oil spill drift forecasting[C]. Proceedings of $7^{\text {th }} \mathrm{Nav}$ Symposium of Military Oceanography, Annapolis, Maryland, United States, 1970: 114-119.

10. $\mathrm{Xu} \mathrm{T}$, Yan B, Sun L. Numerical Simulation of Accidental Oil Spill Diffusion in Xiamen Sea Area[C] //The Twenty-fourth International Ocean and Polar Engineering Conference. International Society of Offshore and Polar Engineers, 2014.

11. Xie Ting, Wang Binxu, Gu Yifan, et al. Numerical simulation of oil spill from vessels in Zhoushan Bojiazui polder project[J]. China Navigation, 2019, 042(003): 110-114.

12. BING Lei. Research on offshore oil spill risk identification and zoning based on remote sensing and GIS[D]. 2019. 